\title{
Comparison of the characteristics of ionospheric parameters obtained from FORMOSAT-3 and digisonde over Ascension Island
}

\author{
Y. J. Chuo ${ }^{1}$, C. C. Lee ${ }^{2}$, W. S. Chen ${ }^{2}$, and B. W. Reinisch ${ }^{3}$ \\ ${ }^{1}$ Department of Information Technology, Ling Tung University, 408 Taichung, Taiwan \\ ${ }^{2}$ General Education Center, Chien Hsin University of Science and Technology, 320 Jhongli, Taiwan \\ ${ }^{3}$ Center for Atmospheric Research, University of Massachusetts, Lowell, MA, USA
}

Correspondence to: Y. J. Chuo (yjchuo@ teamail.ltu.edu.tw)

Received: 7 February 2012 - Revised: 14 February 2013 - Accepted: 4 April 2013 - Published: 3 May 2013

\begin{abstract}
Electron density profile data obtained from the FORMOSAT-3 radio occultation (RO) measurements over Ascension Island are used to study the bottomside thickness parameter $B 0$ in the International Reference Ionosphere (IRI) model, scale height around the F region peak height, and other F2 region parameters. The RO data were collected when the radio occultation occurred at Ascension Island $\left(345.6^{\circ} \mathrm{E}, 8.0^{\circ} \mathrm{S}\right)$ during the solar minimum activity period from May 2006 to April 2008. Results show that the $B 0$ values are in moderate agreement with the ground-based observations in the equinox period (correlation coefficient $r=0.682)$ and winter $(r=0.570)$, with a strong correlation in summer $(r=0.750)$. The seasonal and diurnal variations in $B 0$ over Ascension Island show peak values during the daytime and in winter. In addition, the $B 0$ values were underestimated and overestimated in the RO measurements during the daytime and nighttime, respectively. Moreover, the comparison of scale heights shows that scale heights obtained from the retrieved data and digisonde observations are weakly correlation in all three seasons. Furthermore, although the effective scale height $\left(H_{\mathrm{T}}\right)$ values were reverse of those obtained from the RO measurements and are higher during the nighttime than in the daytime, they are in good agreement with those from ground-based observations. This paper also provides a comprehensive discussion of the effect of the asymmetric ionospheric electron density profiles on RO measurements.
\end{abstract}

Keywords. Radio science (ionospheric physics)

\section{Introduction}

Investigation of the ionospheric electron density profile $N_{\mathrm{e}}(h)$ is an important topic in the study of the ionosphere; for instance, it plays an important role in the study of ionospheric storms, ion compositions, plasma temperature, and the effects on radio communications between satellites and ground receivers. Most ionospheric studies focus on the $\mathrm{F}$ region of the ionosphere because this is the most sensitive area and contains the most important ionospheric dynamics. The $\mathrm{F}$ region is usually divided into three parts. The lowest region, where photochemistry dominates, is called the F1 region. The region where there is a transition from photochemical dominance to diffusion dominance is called the F2 region, and the upper $\mathrm{F}$ region, where diffusion dominates, is called the topside ionosphere. The bottomside ionospheric electron density profile can be measured from ionograms recorded by ground-based observation, the electron density profile of the bottomside F2 layer can be described by the parameters peak density and height of the $\mathrm{F} 2$ layer $(N m \mathrm{~F} 2$ and $h m \mathrm{~F} 2)$, thickness $(B 0)$, and shape $(B 1)$. The electron density profile of the topside ionosphere can be obtained from incoherent scatter radar (ISR), space-borne topside sounder measurements, or empirical models. Ground-based observation methods have spatial and temporal limitations for use in topside ionospheric profile reconstruction; therefore, the empirical model is important for this purpose.

During the past several decades, many ionospheric empirical models have been developed to describe the vertical profile of electron density; these models include Chapman, exponential, parabolic, and Epstein functions (Booker, 1977; Rawer et al., 1985; Rawer, 1988; Di Giovanni and 
Radicella, 1990; Reinisch and Huang, 2001; Reinisch et al., 2004, 2007). The method proposed by Reinisch et al. (2004) is simple and convenient, and the $\alpha$ Chapman function is used to derive the ionospheric topside shape in this method. They assumed a constant scale height around the F2 layer peak height to interpolate the topside ionosphere. Their result shows good agreement with the ISR topside electron density profile during the daytime in the equatorial ionosphere (Reinisch et al., 2004). This method can also applied to modern digisonde to derive vertical electron density profiles in real time. In the past, only the application of ISR or radio occultation (RO) techniques using data from low Earth orbit (LEO) satellites provided an opportunity to study the ionosphere topside and bottomside simultaneously.

In this investigation, we examine and compare the diurnal and seasonal variations in $N m \mathrm{~F} 2, h m \mathrm{~F} 2, B 0$, and effective scale height $\left(H_{\mathrm{T}}\right)$ by using the electron density profile from the Constellation Observing System for Metrology Ionosphere and Climate/Formosa Satellite 3 (COSMIC/FORMOSAT-3) with the variations observed in the corresponding digisonde observations. The FORMOSAT-3 is a scientific satellite, developed by the US and Taiwan, that orbits at an altitude of approximately $500 \mathrm{~km}$. Approximately 1000-2500 ionospheric RO events registered per day by the COSMIC mission have been used to study the various ionospheric phenomena (e.g., He et al., 2009; Liu et al., 2008, 2009, 2011, Luan et al., 2008; Potula et al., 2011; Yue et al., 2010; Zeng et al., 2008). For ground-based observations, we used data from Ascension Island $\left(345.6^{\circ} \mathrm{E}, 8.0^{\circ} \mathrm{S}\right)$ located in the low latitudes area in the Southern Hemisphere.

Validation of $N m \mathrm{~F} 2$ has been the focus of most previous studies on the electron density profile (e.g., Lei et al., 2007; Kelley et al., 2009; Wu et al., 2009; Yue et al., 2010); the results of these studies suggest that the most significant error source is the spherical symmetry assumption in the horizontal direction applied in Abel inversion. Furthermore, Straus (2007) and Wu et al. (2009) showed that error is a relatively large fraction of Abel in the retrieved $h m \mathrm{~F} 2$ corresponding to low latitudes. These findings are based on the comparison of $N m \mathrm{~F} 2$ and $h m \mathrm{~F} 2$ ionospheric parameters. However, because the electron density values can also be derived from profile shapes, we compared the ionospheric RO measurements with the ground-based observation over the low-latitude area to estimate the ionospheric profile and bottomside thickness parameters.

It is widely accepted that the low-latitude area is a complex part of the ionosphere because it is simultaneously affected by dynamo electric fields and thermospheric winds. The Ascension Island observation is nominally located below the southern crest of the equatorial ionization anomaly (EIA) and near the magnetic equator in the F region; thus the distribution of electron density here is higher than that in the neighboring areas. In this paper, we examine the data including the ionospheric profile parameters $N m \mathrm{~F} 2, h m \mathrm{~F} 2, B 0$, and
$H_{\mathrm{T}}$ over Ascension Island from May 2006 to April 2008 during a solar minimum period. In addition, this study is the first to compare the $B 0$ and $H_{\mathrm{T}}$ around the F2-peak height derived from the electron density profiles collected by FORMOSAT3 with ground-based observations at Ascension Island. Although the seasonal variations in $H_{\mathrm{T}}$ derived from COSMIC have been studied by Liu et al. (2011), this is the first time to our knowledge that these values have been compared with ground-based observation to study the effect in the inversion of RO measurements.

\section{Data collection and analysis}

This paper examines the variability in the data of the ionospheric profile parameters $N m \mathrm{~F} 2, h m \mathrm{~F} 2, B 0$, and $H_{\mathrm{T}}$ obtained from space-borne observations and digisonde data from May 2006 to April 2008 during the solar minimum activity periods. The space-borne data were collected from FORMOSAT- 3 observations. The COSMIC/FORMOSAT-3 is a space scientific mission under the cooperation of Taiwan and the US. Six identical microsatellites constituting the COSMIC constellation system were launched into orbits at altitudes of approximate $800 \mathrm{~km}$. The FORMOSAT- 3 observation provided the electron density profiles employed in this study by using an ionospheric RO inversion technique. The details of the data processing and the inversion technique applied to invert RO soundings to ionospheric electron density profiles can be found in the reports of Kuo et al. (2004), Lei et al. (2007), and Schreiner et al. (1999). The retrieved electron density profiles can be downloaded for study from the web address http://tacc.cwb.gov.tw/cdaac/. The electron density data for the region between $5^{\circ} \mathrm{S}$ and $11^{\circ} \mathrm{S}$ and $342^{\circ} \mathrm{E}$ and $349^{\circ} \mathrm{E}$ were extracted. The ionospheric bottomside thickness parameter $B 0$ was calculated using the following expression (Ramakrishnan and Rawer, 1972):

$N_{\mathrm{e}}(h)=N m \mathrm{~F} 2 \cdot \exp \left(-x^{B 1}\right) / \cosh (x)$

where $x=(h m \mathrm{~F} 2-h) / B 0$.

$B 0$ is the slope determined from $h m \mathrm{~F} 2$ corresponding to $h_{0.24}$, which indicates that the electron density decreases to 0.24 times that of $N m \mathrm{~F} 2 . B 1$ is the shape parameter in the International Reference Ionosphere (IRI) model. For $B 0$ measurement, Gulyaeva (1982) suggested that the bottom profile be modified to $h_{0.5}$, which represents half-density height from $h_{0.24}$ in Eq. (1). Furthermore, in this study we followed Gulyaeva's method (Gulyaeva, 1982) to set the $B 1$ parameter at a constant value of 3 to derive the $B 0$ value. $H_{\mathrm{T}}$ at $h m \mathrm{~F} 2$ was derived from the $\alpha$ Chapman profile function (Eq. 2) by using the method followed by Reinisch et al. (2004) to fit the topside profile.

$N_{\mathrm{e}}(h)=N m \mathrm{~F} 2 \cdot \exp \{1 / 2[1-z-\exp (-z)]\}$,

where $z=(h-h m \mathrm{~F} 2) / H_{\mathrm{T}}$. 
In this investigation, we fitted the topside profile retrieved from FORMOSAT-3 measurements by a least-square procedure to derive $H_{\mathrm{T}}$ corresponding to $h m \mathrm{~F} 2$ by using the Eq. (2). Figure 1 shows the electron density profiles obtained using the RO measurements (solid line) and the fitting $\alpha$ Chapman profile (red line) for daytime on 10 September 2006, 10:15 UT (LT = UT + $1 \mathrm{~h}$ ), and the F2-layer peak (red circle). In addition to $H_{\mathrm{m}}$, the scale height nearby the peak height of $F$ region could be determined from the shape of the bottomside electron density profile. This method also uses the $\alpha$ Chapman function with variable scale height $H(h)$ (Rishbeth and Garriott, 1969):

$N_{B}(h)=N_{\mathrm{m}}\left(\frac{H_{\mathrm{m}}}{H(h)}\right)^{\frac{1}{2}} \exp \left[\frac{1}{2}\left(1-y-e^{-y}\right)\right]$,

where $y=\int_{h_{\mathrm{m}}}^{h} \frac{d h}{H(h)}$ and $H_{\mathrm{m}}$ is the scale height at the F2 peak.

Here $N_{B}(h)$ is calculated from the measured $h^{\prime}(f)$ trace in the ionogram. However, this method is applied in the SAO-Explorer software package in digisonde. Although $H_{\mathrm{m}}$ and $H_{\mathrm{T}}$ both are derived from the $\alpha$ Chapman function, there are some differences between them. Further, Huang and Reinisch (2001) mentioned that we can determine $H_{\mathrm{m}}$ from the bottomside profile to estimate for the scale height of the topside profile, i.e., $H_{\mathrm{T}}=H_{\mathrm{m}}$. In addition, we compared the ionospheric profile parameters obtained from the RO measurements with those obtained from ground-based observation at low latitudes in the Southern Hemisphere. The ground-based observation was collected from the Ascension Island digisonde located at a geophysical latitude $8.0^{\circ} \mathrm{S}$ and longitude $345.6^{\circ} \mathrm{E}$ near the equator in the Southern Hemisphere. The analyzed data of manually scaled ionograms were processed by the University of Massachusetts-Lowell (UML) software system SAO-Explorer (http://ulcar.uml.edu/ digisonde.html; Reinisch, 1996; Reinisch and Huang, 1996). The ionospheric electron density profiles were derived using the true height inversion algorithm NHPC, which is included in the SAO-Explorer software package (Reinisch, 1996; Huang and Reinisch, 2001). The ionospheric profile parameters can be obtained using the above-mentioned software in order to compare the results. The $N m \mathrm{~F} 2$ values were derived as shown below.

$N m \mathrm{~F} 2=1.24 \times 10^{10}\left(f_{o} \mathrm{~F}_{2}\right)^{2} \mathrm{elm}^{-3}$,

where $f o \mathrm{~F}_{2}$ is expressed in $\mathrm{MHz}$.

The digisonde data are routinely recorded at $15 \mathrm{~min}$ intervals at the Ascension Island station. In this study, we selected the ionogram in which RO occurred within these limited periods.

RO data offer an additional method for studying ionospheric dynamics and the topside ionosphere. In this study, we focused on the diurnal and seasonal variations in the ionospheric profile parameters, in particular, the topside

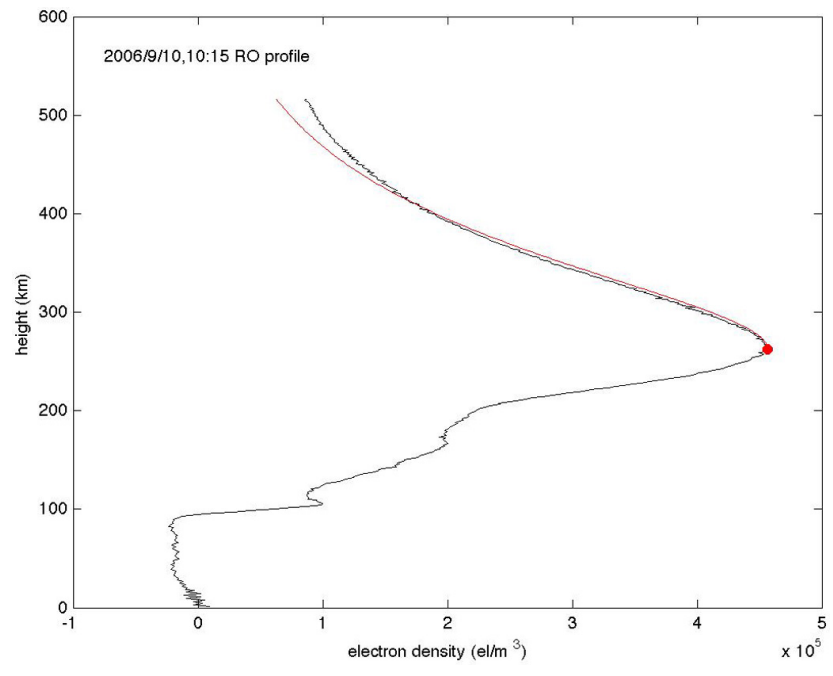

Fig. 1. Example of $H_{\mathrm{T}}$ value by fitting $\alpha$ Chapman function (red line) between the F2-layer peak electron density point (red circle) and the RO measurement (solid line) around 10:15 UT on 10 September 2006 using an $\alpha$ Chapman function.

and bottomside shape parameters $H_{\mathrm{T}}$ and $B 0$ near the EIA area. Thus, we cataloged the data into three seasons as equinox (March, April, September, and October), summer (November-February), and winter (May-August). We then compared the $N m \mathrm{~F} 2, h m \mathrm{~F} 2, B 0$, and $H_{\mathrm{T}}$ values derived from RO measurements and from digisonde observations by qualifying their differences during the period May 2006April 2008 to elucidate possible asymmetric effects on the four parameters.

\section{Results}

In this investigation, we examined two datasets to study characteristics of the ionospheric profile: the retrieved data and the ground-based observations. The RO measurements do not include entire daytime periods, and the solar activities are all in minimum phases. Therefore, we gathered all the data from May 2006 to April 2008 to represent $1 \mathrm{yr}$. The digisonde dataset was obtained on days when RO occurred. The annual distributions of $N m \mathrm{~F} 2, h m \mathrm{~F} 2, B 0$, and $H_{\mathrm{T}}$ were obtained by considering the median values on the days for each month, and the median values were derived from digisonde observations and RO measurements, as shown in the left and right panels in Fig. 2, respectively. Figure 2a and b show the annual distribution in $N m \mathrm{~F} 2$ that was obtained from digisonde and RO data, respectively. Two peaks were apparent in the daytime during the period October-April, both occurring simultaneously in digisonde and RO measurements.

In the case of $h m \mathrm{~F} 2$, the two datasets also showed a similar trend, with two apparent peaks appearing in the daytime in the summer season (November-February). In addition, a trough appeared at 07:00-08:00 LT (Fig. 2c-d). In the case 

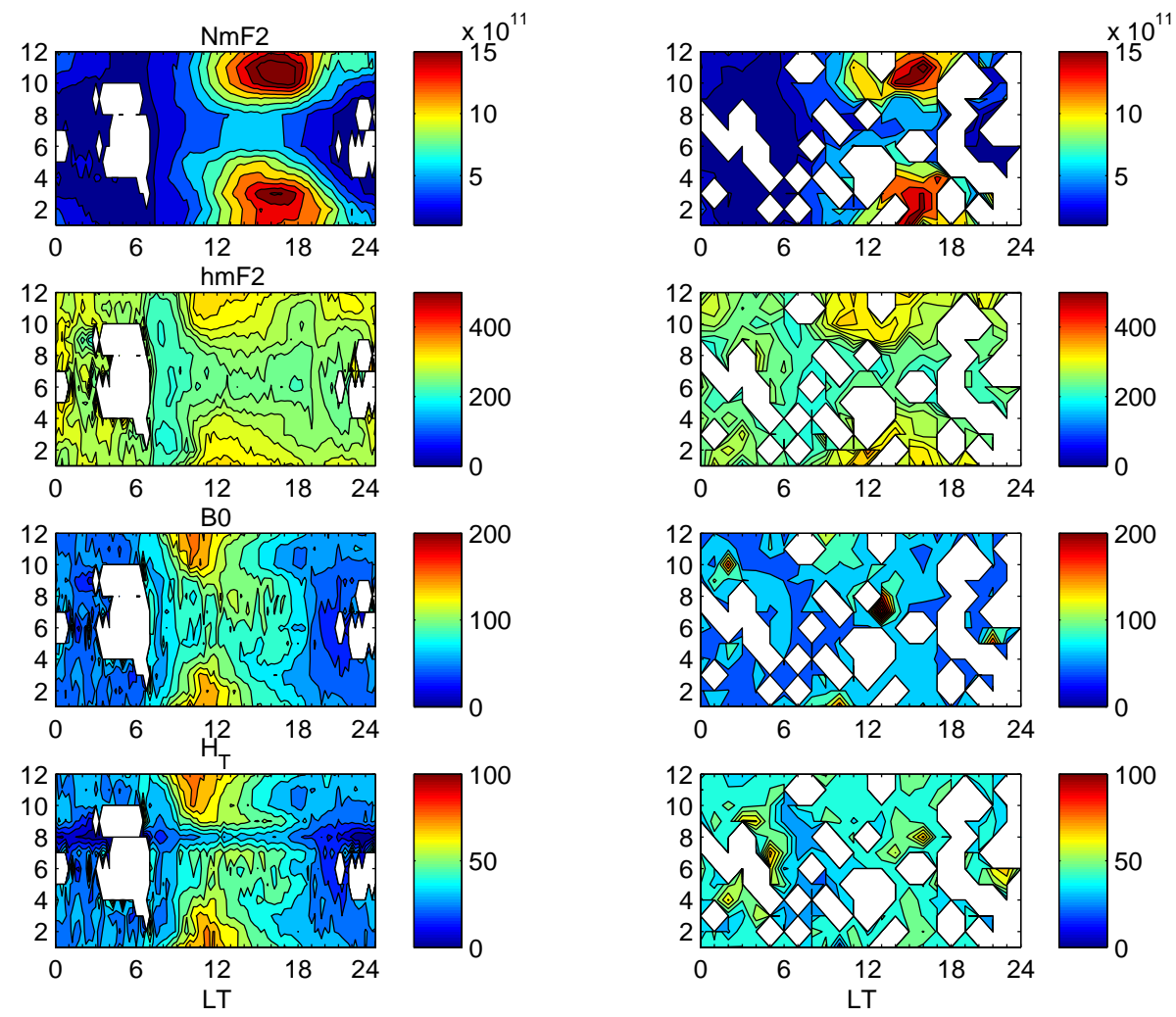

Fig. 2. Variations in $N m \mathrm{~F} 2, h m \mathrm{~F} 2, B 0$, and $H_{\mathrm{T}}$ values measured from ground-based observations (left panels) and RO measurements (right panels).

of the $B 0$ parameter, two apparent peaks occurred at 10:0012:00 LT in the summer season in the digisonde observation; a similar trend appeared in the RO measurements. However, the values were underestimated (Fig. 2e-f).

In the case of $H_{\mathrm{m}}$, ground-based observation showed two peak values at 10:00-13:00 LT in October-March, and daytime values were greater than the nighttime values in all seasons. The RO measurements differed completely from the digisonde data (Fig. $2 \mathrm{~g}-\mathrm{h}$ ). The result corresponding to RO showed a conspicuous peak during the pre-sunrise periods in April-September. Figure 3 shows the diurnal variations in $N m \mathrm{~F} 2, h m \mathrm{~F} 2, B 0$, and $H_{\mathrm{T}}$ in the equinoctial season. Gray dots and the dotted line respectively denote the measurements and average hourly point from RO inversion, and the red asterisk represents the monthly median of digisondederived values.

Figure 3a shows that the RO measurements in $N m \mathrm{~F} 2$ followed a trend similar to that of digisonde observations. Only slight underestimation and overestimation were apparent at 12:00 LT and at 20:00-00:00 LT. Figure 3e shows a high correlation (correlation coefficient $r=0.962$ ) between RO measurements and digisonde observations in the equinox period. Figure $3 \mathrm{~b}$ represents the diurnal variation in $h m \mathrm{~F} 2$ in the equinox period and shows a trend similar to that of digisonde data with a daytime peak during 11:00-15:00 LT and a trough at 07:00-09:00 LT. These results indicate that RO measurements were overestimated and underestimated during 11:0015:00 LT and 21:00-06:00 LT, respectively. Figure $3 \mathrm{f}$ shows a good correlation $(r=0.872)$ in $h m \mathrm{~F} 2$ between $\mathrm{RO}$ and digisonde data. Figure $3 \mathrm{c}$ illustrates the diurnal variation in $B 0$ with a peak value occurring at 10:00-12:00 LT both in digisonde and RO measurements. These results indicate that RO measurements were underestimated and overestimated at 08:00-14:00 LT and 21:00-06:00 LT, respectively. Figure 3g shows a middle correlation $(r=0.682)$ in $B 0$ values between the digisonde and RO measurements in the equinox period. Figure $3 \mathrm{~d}$ represents the diurnal variation in $H_{\mathrm{T}}$ in the equinox period, showing that the behaviors of RO measurements and digisonde data at 00:00-06:00 LT were completely different. These results show an increase from 08:00 LT, with the maximum value at 11:00 LT in digisonde data. RO measurements indicate that the nighttime values were greater than the daytime values, and a trough appeared at 06:0010:00 LT. Figure $3 \mathrm{~h}$ shows a weak correlation $(r=0.195)$ between the RO measurements and digisonde data in the equinox period.

Figures 4 and 5 represent the same variability of the four ionospheric profile parameters, clearly shown in Fig. 3, during summer and winter, respectively. In the case of summer, the $N m \mathrm{~F} 2$ and $h m \mathrm{~F} 2$ values from the $\mathrm{RO}$ measurements 

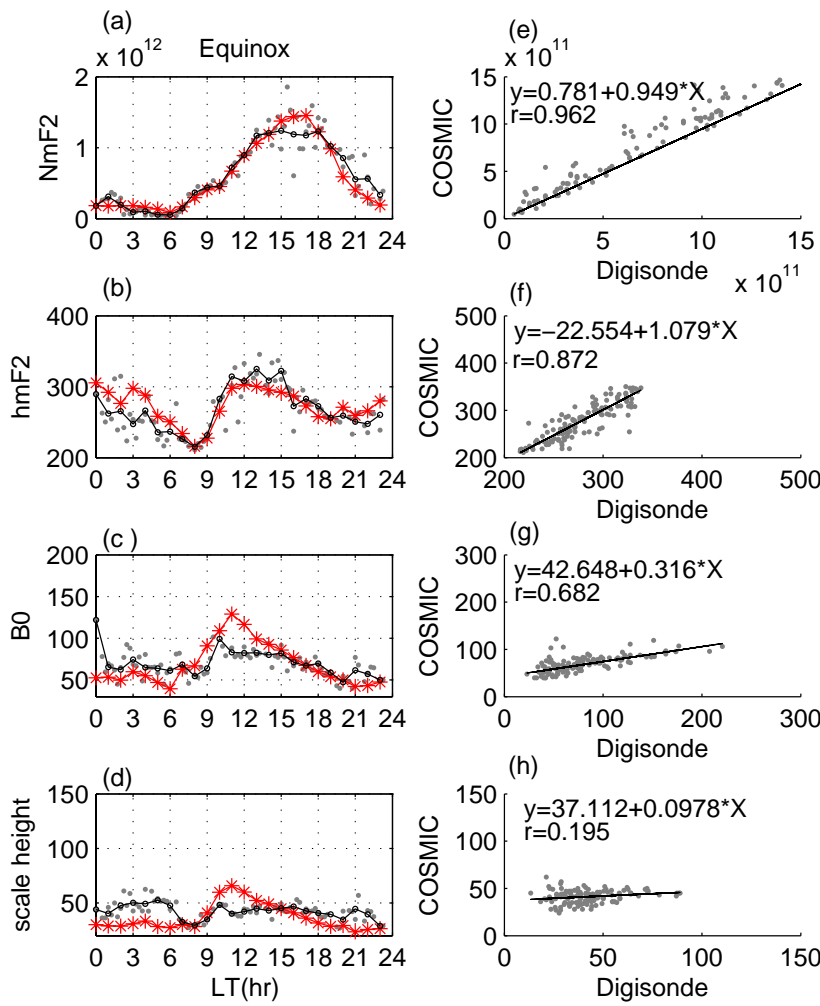

Fig. 3. (a)-(d) Comparison of the diurnal variations obtained from ground-based observations (red asterisk) and RO measurements (circled line) and (e)-(h) scatter plots for the $N m \mathrm{~F} 2, h m \mathrm{~F} 2, B 0$, and $H_{\mathrm{T}}$ parameter in the equinox period.

and those derived from digisonde observations were in good agreement (Fig. 4a-b); the two datasets have high correlation coefficients of 0.975 and 0.867 in terms $N m \mathrm{~F} 2$ and $h m \mathrm{~F} 2$, respectively (Fig. $4 \mathrm{e}-\mathrm{f}$ ). In addition, the $B 0$ parameter derived from $\mathrm{RO}$ measurements and digisonde-derived data showed a similar tendency, with a peak value appearing at 10:00-11:00 LT (Fig. 4c). These results illustrate an underestimation and overestimation at 08:00-14:00 LT and 00:00-06:00 LT, respectively. Figure 4g shows a medium correlation coefficient of 0.750 . Moreover, $H_{\mathrm{T}}$ derived from digisonde data showed a daily variation and a peak value occurrence at 12:00 LT; however, the daily variation was not apparent in the RO measurements (Fig. 4d). The illustration shows a smaller difference between the retrieved and groundbased data during 15:00-23:00 LT (Fig. 4d).

The correlation of the $H_{\mathrm{T}}$ values obtained from RO measurements and those obtained from the digisonde-derived data was also weak $(r=0.473)$ in summer (Fig. 4h). In the winter season, the variation in $N m \mathrm{~F} 2$ from RO measurements and ground-based observations showed a good agreement and strong correlation $(r=0.915)$ (Fig. 5a and e). These results indicate that the RO measurements were underestimated at 23:00-07:00 LT. The result for $h m \mathrm{~F} 2$ represents a similar trend with a high correlation $(r=0.729)$
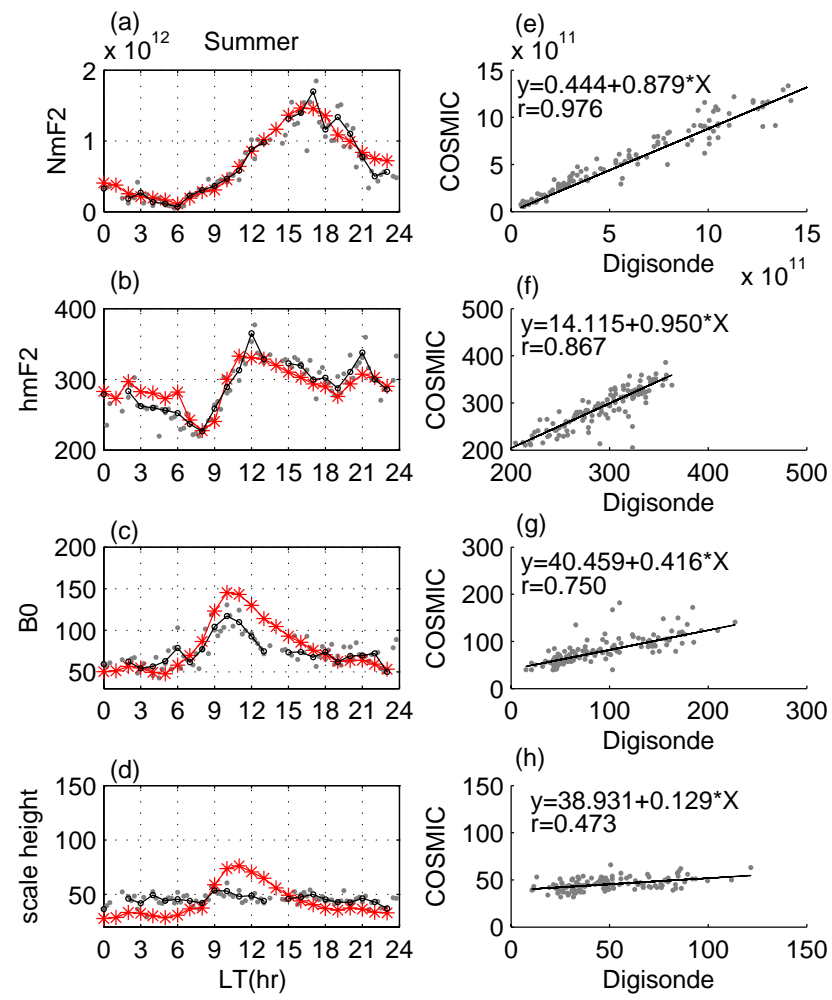

Fig. 4. (a)-(d) Comparison of the diurnal variations obtained from ground-based observations (red asterisk) and RO measurements (circled line) and (e)-(h) scatter plots for the $N m \mathrm{~F} 2, h m \mathrm{~F} 2, B 0$, and $H_{\mathrm{T}}$ parameter in the summer.

and shows that the RO-derived values are generally underestimated (Fig. $5 \mathrm{~b}$ and $\mathrm{f}$ ). The illustration of $B 0$ shows that the RO measurement was underestimated/overestimated during the daytime/nighttime in winter (Fig. $5 \mathrm{c}$ ). The $B 0$ values represent a higher diurnal variation in the daytime than that in the nighttime. In addition, a trough observed in ground-based derived data was not obvious in retrieved data for 18:0021:00 LT. Furthermore, a medium correlation $(r=0.570)$ appeared with a similar trend (Fig. $5 \mathrm{~g}$ ).

In the case of $H_{\mathrm{T}}$, the digisonde-derived values showed greater diurnal variation in the daytime and a trough was observed at 20:00 LT (Fig. 5d). The values derived from the retrieved data also showed diurnal variation; however, the result is in contrast with that obtained from ground-based data. A daytime increase starting at 09:00 LT was also observed in RO measurements, and the values were underestimated at 09:00-16:00 LT. Thereafter, the digisonde-derived values decreased to the minimum value (approximately $21 \mathrm{~km}$ ), and the retrieved data continued to increase to higher values (approximately $40-65 \mathrm{~km}$ ) during the nighttime period. The correlation coefficient was 0.270 , representing a weak correlation (Fig. 5h).

To summarize, the statistics of the $N m \mathrm{~F} 2$ parameter was in good agreement between the retrieved and observed 

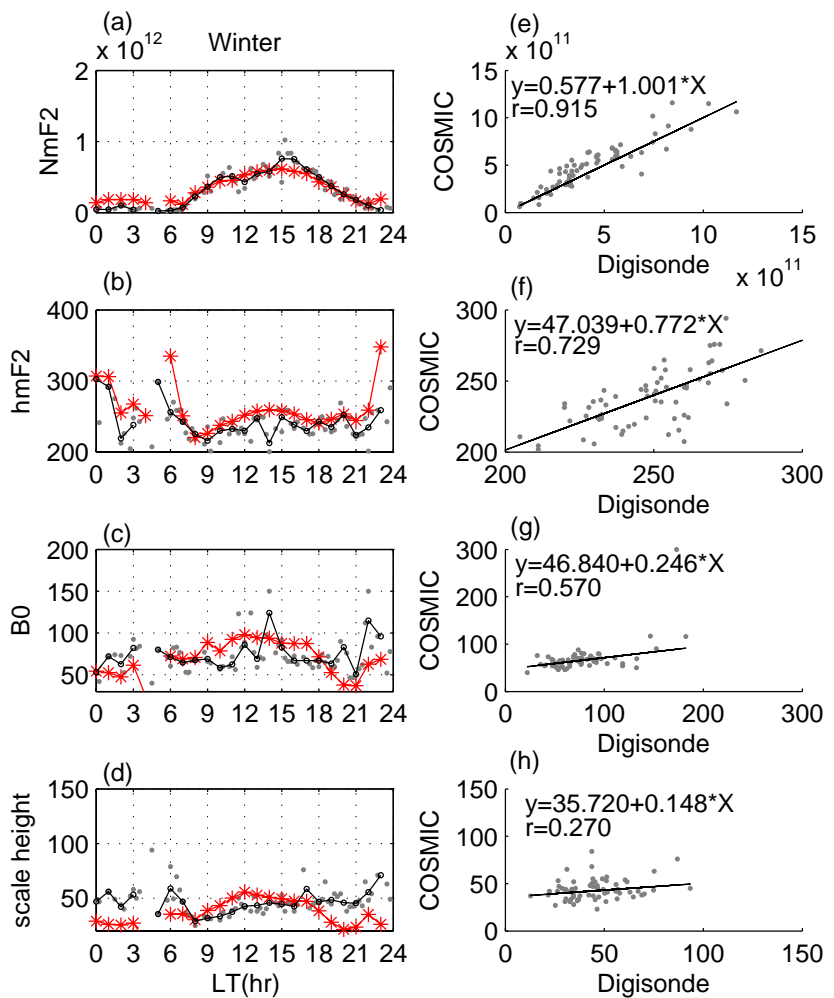

Fig. 5. (a)-(d) Comparison of the diurnal variations obtained from ground-based observations (red asterisk) and RO measurements (circled line) and (e)-(h) scatter plots for the $N m \mathrm{~F} 2, h m \mathrm{~F} 2, B 0$, and $H_{\mathrm{T}}$ parameter during winter.

digisonde data for all three seasons. The correlation values were $0.962,0.975$, and 0.915 in equinox, summer, and winter seasons, respectively. The research of Wu et al. (2009) of the global asymmetry error in ionospheric RO measurements indicates that the error is larger in winter and smaller in the equinox period. In addition, Chuo et al. (2011) indicated that the $N m \mathrm{~F} 2$ is better in summer and worse in winter over $\mathrm{Ji}$ camarca during the solar minimum phase. This study shows that the correlation is almost the same for all seasons with a slight decrease in winter, which was caused by the asymmetric distribution of the electron density and lower/higher electron density occurring in summer/winter over the equatorial region. These results are in good agreement with the previous studies.

During the same periods, $N m \mathrm{~F} 2$ was overestimated at the equator (Chuo et al., 2011) and underestimated at low latitudes (present study). In the case of $h m \mathrm{~F} 2$, the correlation values $(0.872,0.867$, and 0.729$)$ indicate that the accuracy of the retrieved data was highest in the equinox period and lowest in winter. These results also agree with those of Chuo et al. (2011), who studied the retrieved density profiles over equatorial latitudes and concluded that the RO measurements were better in $N m \mathrm{~F} 2$ than in $h m \mathrm{~F} 2$. The $B 0$ parameter result showed a medium correlation in the equinox period (0.682), summer (0.750), and winter (0.570). Chuo et al. (2011) reported a similar result in their study of RO measurements in the Jicamarca region; these measurements indicated a weak $B 0$ parameter correlation between the retrieved data and ground-based inverse values. The apparent increase in $B 0$ during 00:00-04:00 LT in summer was not observed in the Ascension Island area. In addition, the correlation was lower in low-latitude areas (present study) than near the equator (Chuo, et al., 2011). Moreover, the $B 0$ parameter in both areas was underestimated during the daytime in all seasons.

What is the influence on $B 0$ ? Equation (1) shows that the $B 0$ value is strongly associated with both $N m \mathrm{~F} 2$ and $h m \mathrm{~F} 2$. However the result mentioned above indicates that the $N m \mathrm{~F} 2$ is in good fitness with the ground-based observation and also highly reliable. Therefore, the $B 0$ parameter could be more dependent on the variation of $h m \mathrm{~F} 2$. During the past years, Liu et al. (2010) studied the variation of $B 0$ during 12:00-14:00 LT around the low latitudes by the electron profiles retrieved from FORMOSAT-3/COSMIC radio occultation measurements. They showed a seasonal variation in $B 0$, and the value was higher in solstice months and lower in equinox months. This result is similar to the outcome of Fig. $2 b$ during the same time period. Nevertheless, the result could be caused by errors. Yue et al. (2010) indicated that the reliability of the retrieved electron density profile is lower in low-latitude regions and at low altitudes. They also mentioned that the errors were caused by the horizontal inhomogeneity of electron density. In this study, the results of Figs. 3-5 also show that the $B 0$ derived from the retrieved measurements is overestimated during noontime. During the same period, the $h m \mathrm{~F} 2$ is underestimated from the RO measurements. This result satisfies the suggestion of Yue et al. (2010) that the inhomogeneity distribution of horizontal electron density underestimates the $h m \mathrm{~F} 2$ and also causes a shape change in ionospheric bottomside profile.

The $H_{\mathrm{T}}$ results show poor correlation or nearly noncorrelation $(r=0.195,0.473$, and 0.270$)$ between the retrieved data and ground-based values. The $H_{\mathrm{T}}$ values were generally underestimated in the daytime (09:00-15:00 LT) and overestimated in the nighttime (17:00-07:00 LT) in all three seasons. Potula et al. (2011) compared the topside vertical scale height (VSH) obtained from the RO measurements and from the IRI model in 2007 and indicated that the latitudinal distribution was in contrast with the result predicated by the IRI model for daytime.

In the case of the topside ionosphere, dynamical processes play an important role, particularly in the fountain effect (Rishbeth and Garriott, 1969), which is due to a strong vertical $\boldsymbol{E} \times \boldsymbol{B}$ drift at the equator that leads to a simultaneous electron density decrease in the ionosphere bottomside and increase in the topside. This increased plasma and subsequent change in thickness and scale height of the topside ionosphere begins at 12:00 LT (Liu et al., 2008; Potula et al., 2011). Equation (2) indicates that the $H_{\mathrm{T}}$ value is determined by the plasma density and $h m \mathrm{~F} 2$. Therefore, the 
fountain effect leads to an increase in the plasma content in the topside ionosphere during the daytime, and this delays $\mathrm{RO}$ resulting in the underestimation of $N m \mathrm{~F} 2, B 0$, and $H_{\mathrm{T}}$ during the daytime. This result is in a good agreement with the results of Chuo et al. (2011) who studied a comparison between RO and ground-based observations in Jicamarca. During the nighttime, the $B 0$ and $H_{\mathrm{T}}$ parameters were nearly overestimated in all three seasons, particularly in winter. The difference in $B 0$ was smaller than that in $H_{\mathrm{T}}$ during the nighttime, particularly in summer. These results indicate that electron distribution plays an important role in recreating the ionospheric shape from retrieved data.

\section{Conclusions}

In the present paper, we describe the $\mathrm{F}$ layer profile characteristics using RO measurements from FORMOSAT-3 and Ascension Island digisonde observations. Monthly median values of the ionospheric F2-layer profile parameters $N m \mathrm{~F} 2, h m \mathrm{~F} 2, B 0$, and $H_{\mathrm{T}}$ were obtained during the period May 2006-April 2008, when solar activity was low. To the best of our knowledge, our study is the first to compare $B 0$ and $H_{\mathrm{T}}$ values obtained from FORMOSAT-3 RO measurements and ground-based observations over the low-latitude area in the Southern Hemisphere. The major results of this study are summarized in the following points:

1. Two separate measurements of $N m \mathrm{~F} 2$ in the low-latitude region derived from satellite radio occultation and digisonde measurements show a similar diurnal variation and a high correlation, during the solar minimum period. In addition, the fountain effect caused retrieved data to be underestimated in the equinox period and overestimated in summer and winter at 15:00-18:00 LT. These results are in good agreement with those of Fejer et al. (2008), who studied the ROCSAT-1 observations and indicated that the $\boldsymbol{E} \times \boldsymbol{B}$ drift is strong in the equinox period, moderate in December, and weak in the June solstice. The results also agree with those of Chuo et al. (2011), who studied RO measurements in Jicamarca during the same period of $N m \mathrm{~F} 2$ underestimation/overestimation in summer/equinox, respectively. Furthermore, the $N m \mathrm{~F} 2$ results are comparable to those of Chuo et al. (2011), indicating a higher correlation in low latitudes than at the equator. These results suggest that the asymmetric nature of the electron density plays an important role in RO measurement.

2. The $h m \mathrm{~F} 2$ values obtained from retrieved data and ground-based observations also show good agreement. The result indicates a high correlation between RO measurements and ground-based observations with the stronger (0.872) during the equinox and the lower correlation (0.729) during winter in the low-latitude area. This result is similar to that obtained by Chuo et al. (2011) for the equatorial region and indicates that $\mathrm{RO}$ measurements of $h \mathrm{mF} 2$ are underestimated/overestimated at 12:00-18:00/00:00-06:00 LT in the equinox period and summer, and are overestimated during the entire day in winter. These results are also in good agreement with those of Wu et al. (2009), who studied the global asymmetry error in ionospheric RO measurements and concluded that the error is larger in winter.

3. This study is the first time comparing the $B 0$ parameter in retrieved data with ground-based observations at Ascension Island. Our results indicate that the retrieved data follow a similar trend as that of groundbased observations; however, RO measurements differ An underestimation and overestimation during the daytime (09:00-15:00 LT) and nighttime (21:00-05:00 LT), respectively, were observed for all three seasons. This underestimation is similar to that reported at the equator (Chuo et al., 2011), indicating that the correlation is stronger in equatorial area than at Ascension Island. Further, the errors were caused by the $h m \mathrm{~F} 2$ to be underestimated because of the horizontal inhomogeneity of electron density.

4. To the best of our knowledge, this study is the first to compare $H_{\mathrm{T}}$ retrieved from RO measurements and digisonde observations; the results show a complicated seasonal variation in the $H_{\mathrm{T}}$ retrieved from FORMOSAT-3 ionospheric RO data for Ascension Island during periods of low solar activity. The $H_{\mathrm{T}}$ values retrieved from $\mathrm{RO}$ measurements are generally higher at nighttime than at daytime, particularly in the equinox period and winter. The seasonal variation in $H_{\mathrm{T}}$ indicates a peak value at daytime/nighttime in summer/winter for ground-based observations and RO measurements, respectively. The correlation between the retrieved data and ground-based observations is very weak; however, the correlation coefficient is higher $(0.473)$ in summer than in equinox and winter $(0.195 / 0.270)$.

Acknowledgements. The authors greatly thank Editor-in-chief Mike Pinnock and reviewers for their valuable comments and suggestions. We would like to thank the NSPO of Taiwan and UCAR of USA for providing the FORMOSAT-3/COSMIC data online through CDAAC. This work was supported by the grants of National Science Council NSC101-2111-M-275-001.

Editor-in-chief M. Pinnock and Topical Editor P.-L. Blelly thank one anonymous referee for her/his help in evaluating this paper.

\section{References}

Booker, H. G.: Fitting of multi-region ionospheric profiles of electron density by a single analytic function of height, J. Atmos. 
Terr. Phys., 39, 619-623, 1977.

Chuo, Y. J., Lee, C. C., Chen, W. S., and Reinisch, B. W.: Comparison between bottomside ionospheric profile parameters retrieved from FORMOSAT3 measurements and ground-based observations collected at Jicamarca, J. Atmos. Solar-Terr. Phys., 73, 1665-1673, doi:10.1016/j.jastp.2011.02.021, 2011.

Di Giovanni, G. and Radicella, S. M.: An analytical model of the electron density profile in the ionosphere, Adv. Space Res., 10, 27-30, 1990.

Fejer, B. G., Jensen, J. W., and Su, S.-Y.: Quiet-time equqtorial $\mathrm{F}$ region vertical plasma drift model derived from ROCSAT-1 observations, J. Geophys. Res., 113, A05304, doi:10.1029/2007JA012801, 2008.

Gulyaeva, T. L.: Implementation of a new characteristic parameter into the IRI sub-peak electron density profile, Adv. Space Res., 2, 191-194, 1982.

He, M., Liu, L., Wan, W., Ning, B., Zhao, B., Wen, J., Yue, X., and Le, H.: A study of the Weddell Sea Anomaly observed by FORMOSAT-3/COSMIC, J. Geophys. Res., 114, A12309, doi:10.1029/2009JA014175, 2009.

Huang, X. and Reinisch, B. W.: Vertical electron content from ionograms in real time, Radio Sci., 36, 335-342, 2001.

Kelley, M. C., Wong, V. K., Aponte, N., Coker, C., Mannucci, A. J., and Komjathy, A.: Comparison of COSMIC occultation-based electron density profiles and TIP observation with Arecibo incoherent scatter radar data, Radio Sci., 44, RS4011, doi:10.1029/2008RS004087, 2009.

Kuo, Y.-H., Wee, T.-K., Sololovskiy, S., Rocken, C., Schreiner, W., Hunt, D., and Anthes, R. A.: Inversion and error estimation of GPS radio occultation data, J. Meteorol. Soc. Jpn., 82, 507-531, 2004.

Lei, J., Syndergaard, S., Burns, A. G., Solomon, S. C., Wang, W., Zeng, Z., Roble, R. G., Wu, Q., Kuo, Y.-H., Holt, J. M., Zhang, S.-R., Hysell, D. L., Rodrigues, F. S., and Lin, C. H.: Comparison of COSMIC ionospheric measurements with ground-based observations and model predictions: preliminary results, J. Geophys. Res., 112, A07308. doi:10.1029/2006JA012240, 2007.

Liu, L., He, M., Wan, W., and Zhang, M.-L.: Topside ionospheric scale heights retrieved from Constellation Observating System for Meteorology, Ionosphere, and Climate radio occultation measurements, J. Geophys. Res., 113, A10304, doi:10.1029/2008JA013490, 2008.

Liu, L., Zhao, B., Wan, W., Ning, B., Zhang, M.-L., and He, M.: Seasonal variations of the ionospheric electron densities retrieved from Constellation Observating System for Meteorology, Ionosphere, and Climate radio occultation measurements, J. Geophys. Res., 114, A02302, doi:10.1029/2008JA013819, 2009.

Liu, L., Wan, W., Ning, B., Zhang, M.-L., He, M., and Yue, X.: Longitudinal behaviors of the IRI-B parameters of the equatorial electron density profiles retrieved from FORMOSAT-3/COSMIC radio occultation measurements, Adv. Space Res., 46, 10641069, 2010.

Liu, L., Le, H., Chen, Y., He, M., Wan, W., and Yue, X.: Features of the middle- and low-latitude ionosphere during solar minimum as revealed from COSMIC radio occultation measurements, J. Geophys. Res., 116, A09307, doi:10.1029/2011JA016691, 2011.
Luan, X., Wang, W., Burns, A., Solomon, S. C., and Lei, J.: Midlatitude nighttime enhancement in $\mathrm{F}$ region electron density from global COSMIC measurements under solar minimum winter condition, J. Geophys. Res., 113, A09319, doi:10.1029/2008JA013063, 2008.

Potula, B. S., Chu, Y.-H., Uma, G., Hsia, H.-P., and Wu, K.-H.: A global comparative study on the ionospheric measurements between COSMIC radio occultation technique and IRI model, J. Geophys. Res., 116, A02310, doi:10.1029/2010JA015814, 2011.

Ramakrishnan, S. and Rawer, K.: Model electron density profiles obtained by empirical procedures, in Space Research XII, Proceedings of the Fourteen Plenary Meeting, Seattle, Wash; German Democratic Republic; 18 June-2 July 1971, pp. 1253-1259, Akademie, Berlin, 1972.

Rawer, K.: Synthesis of ionospheric electron density profiles with Epstein functions, Adv. Space Res., 8, 191-199, 1988.

Rawer, K., Bilitza, D., and Gulyaeva, T. L.: New formulas for IRI electron density profile in the topside and middle ionosphere, Adv. Space Res., 5, 3-12, 1985.

Reinisch, B. W.: Modern ionosondes, in: Kohl, H., Rüster, R., and Schlegel, K. (Eds.): Modern Ionospheric Science, European Geophysical Society, Katlen- burg-Lindau, Germany, pp. 440-458, 1996.

Reinisch, B. W. and Huang, X.: Low latitude digisonde measurements and comparison with IRI, Adv. Space Res., 18, 5-12, 1996.

Reinisch, B. W. and Huang, X.: Deducing topside profiles and total electron content from bottomside ionograms, Adv. Space Res., 27, 23-30, 2001.

Reinisch, B. W., Huang, X.-Q., Belehaki, A., Shi, J.-K., Zhang, M.-L., and Ilma, R.: Modeling the IRI topside profile using scale heights from ground-based ionosonde measurements, Adv. Space Res., 34, 2026-2031, 2004.

Reinisch, B. W., Nsumei, P., Huang, X., and Bilitza, D. K.: Modeling the F2 topside and plasmasphere for IRI using IMAGE/RPI and ISIS data, Adv. Space Res., 39, 731-738, 2007.

Rishbeth, H. and Garriott, Q. K.: Introduction to Ionospheric Physics, Academic Press, New York, 1969.

Schreiner, W. S., Sokolovskiy, S. V., Rocken, C., and Hunt, D. C.: Analysis and validation of GPS/MET radio occultation data in the ionosphere, Radio Sci., 34, 949-966, 1999.

Straus, P. R.: Ionospheric climatology derived from GPS occultation observa- tions made by the ionospheric occultation experiment, Adv. Space Res., 39, 793-802, 2007.

Wu, X., Hu, X., Gong, X., Zhang, X., and Wang, X.: Analysis of inversion errors of ionospheric radio occultation, GPS Solut., 13, 231-239. doi:10.1007/s10291-008-0116-x, 2009.

Yue, X., Schreiner, W. S., Lei, J., Sokolovskiy, S. V., Rocken, C., Hunt, D. C., and Kuo, Y.-H.: Error analysis of Abel retrieved electron density profiles from radio occultation measurements, Ann. Geophys., 28, 217-222, doi:10.5194/angeo-28-217-2010, 2010.

Zeng, Z., Burns, A., Wang, W., Lei, J., Solomon, S., Syndergaard, S., Qian, L., and Kuo, Y.: Ionospheric annual asymmetry observed by the COSMIC radio occultation measurements and simulated by the TIEGCM, J. Geophys. Res., 113, A07305, doi:10.1029/2007JA012897, 2008. 